\title{
Analysis of the Heat Transfer Enhancement in Triangular Microchannel with a Trapezoidal Corrugated Surface and Hybrid Nanofluid
}

\author{
Hadi O. Basher \\ Mechanical Engineering Department, College of Engineering, Wasit University, Al-kut-Wasit 52001, Iraq
}

Corresponding Author Email: hadi@uowasit.edu.iq

https://doi.org/10.18280/ijht.390604

Received: 8 September 2021

Accepted: 26 December 2021

\section{Keywords:}

triangular microchannel, trapezoidal corrugated wall, hybrid nanofluid, laminar flow

\begin{abstract}
The current study has investigated the effects of different wave amplitudes of the trapezoidal corrugated surface in a triangular microchannel on the thermal and hydraulic properties using the finite volume method. The laminar forced convection of $\mathrm{CuO}$-water nanofluid, Ag-water nanofluid, and $\mathrm{CuO}-\mathrm{Ag} /$ water hybrid nanofluid as working fluid over Reynolds number and nanoparticle volume fraction ranges of 5-500 and 0-0.03, respectively, has been examined. The base of the triangular channel was exposed to 25,000 $\mathrm{W} / \mathrm{m}^{2}$ of heat flux. The results indicate that the shape and wave amplitude have no significant effect on the behavior of streamlines at $\mathrm{Re}=5$, except in the regions of the crest of the wave where the velocity increases slightly due to the convergence section. The streamlines began to change in shape, especially at the wave amplitude of $125 \mathrm{~m}$ and $\mathrm{Re}$ above 100, while the temperatures on the corrugated surface decreased as the Reynolds number increased. Furthermore, the skin friction coefficient at $\operatorname{Re}=5$ for all wave amplitudes is about 10 times higher than the skin friction coefficient at $\operatorname{Re}=100$. In addition, the results showed that adding a small amount of $\mathrm{Ag}$ nanoparticles to the $\mathrm{CuO}$ nanofluid enhanced the thermal conductivity of the fluid and thus improved the heat transfer rate.
\end{abstract}

\section{INTRODUCTION}

Recently, researchers have made strenuous efforts to keep pace with technological development in various industries in terms of developing heat transfer enhancement research. These researches focused on disrupting the boundary layer, forming secondary flows, increasing fluid thermal conductivity, and increasing flow rate in heat exchangers [1]. Micro-scale industries, such as electronic devices, require new and modern heat transfer methods. Thus, microchannels are used in many industrial applications to improve heat transfer and reduce system size. Reducing the size of the system has an essential effect in reducing the cost, lightweight, cooling system, conserving the environment and the space occupied by the system [2]. In this regard, the triangular channel has played a major role in improving heat transfer in microscale systems [3]. Another method to improve heat transfer is to add high thermal conductivity Nanopowders to conventional fluids [48]. Researchers recently developed a new fluid called hybrid nanofluid after discovering that some Nanofluid has defects such as low thermal conductivity and instability, especially metal oxide with spherical grains Nanofluid [9-12]. Many researchers have investigated the effects of hybrid nanofluids, surface shapes, and microchannel cross-sections on flow behavior and heat transfer rate in both turbulent and laminar flow [13-24].

Bahiraei et al. [23] studied the effect of hybrid nanofluid on the thermal performance in a micro-channel. The microchannel has been equipped with secondary channels and ribs. The results showed that the temperature of the bottom surface of the channel decreased by 3.42 when the nanofluid concentration increased from 0 to $0.1 \%$ at $\mathrm{Re}=100$. Mashayekhi et al. [25] conducted a numerical analysis of heat transfer and fluid flow in a double-layered microchannel with sinusoidal walls. The effect of different concentrations of $\mathrm{Al}_{2} \mathrm{O}_{3}-\mathrm{Cu} /$ water nanofluid ranged between $0-2 \%$ on the Nusselt number and pressure drop have studied. The results indicated that the $23 \%$ Nusselt number enhancement was obtained at the highest concentration and highest Reynolds

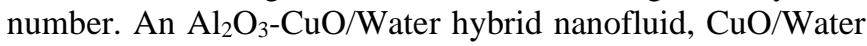
nanofluid, and $\mathrm{Al}_{2} \mathrm{O}_{3} /$ Water nanofluid in pentagonal, triangular micro-channel were studied by Heidarshenas et al. [26]. The pentagonal, triangular micro-channel increased the rate of heat transfer by $12.3 \%$ and the pressure drop by 16.5 percent. When it comes to nanofluids, the $\mathrm{Al}_{2} \mathrm{O}_{3}-\mathrm{CuO} /$ Water Hybrid nanofluid outperformed $\mathrm{Al}_{2} \mathrm{O}_{3}$ and $\mathrm{CuO} /$ Water nanofluids by $5.5 \%$ and $4.2 \%$ respectively. A hybrid nanofluid of graphene and platinum/water has been used by Rabiei et al. [27] to improve the cooling efficiency of a cylindrical microchannel with a wavy-shaped fin. The results of the preliminary numerical study showed that the maximum improvement of the average heat transfer coefficient was $13387 \mathrm{~W} / \mathrm{m}^{2} \mathrm{~K}$ at the highest concentration of nanomaterials, the highest wave capacity, while the lowest thermal resistance and the highest pumping power was $0.6 \mathrm{~W}$ and $0.031 \mathrm{~K} / \mathrm{W}$, respectively. Ghachem et al. [28] analyzed the impact of parameters such as wavenumber, nanoparticles concentration of $\mathrm{Al}_{2} \mathrm{O}_{3}-\mathrm{SiO}_{2}$, and $\mathrm{Al}_{2} \mathrm{O}_{3}-\mathrm{Cu}$ /water hybrid nanofluids on the rate of heat transfer in the wavy microwave channel. The results showed that the increased volume concentration had a significant effect in lowering the exit temperature of the fluid. In addition, the results demonstrated that the increase in the 
number of waves also contributed to lowering the temperature of the fluid exit. Sarvar et al. [29] used $\mathrm{Al}_{2} \mathrm{O}_{3}-\mathrm{SiO}_{2} /$ water and $\mathrm{Al}_{2} \mathrm{O}_{3}-\mathrm{Cu} /$ water hybrid nanofluids in a microchannel heatsink to cool the CPU. the results demonstrated that both the hybrid nanofluid had significantly reduced the surface temperature compared to the effect of water. Moreover, the hybrid nanofluids have a better heat transfer enhancement than pure water but this enhancement of heat transfer was combined with higher pumping power. Alnaqi et al. [30] have used hybrid nanofluids MWCNTs $-\mathrm{SiO}_{2} / \mathrm{EG}-\mathrm{H}_{2} \mathrm{O}$ to cool a heat sink containing a set of zigzag micro-channels. The numerical study showed that increasing the concentration of nanoparticles and the zigzag height has caused a significant improvement in heat transfer, but this increase was accompanied by an increase in pressure drop. Water-based hybrid nanofluids with $\left(\mathrm{Al}_{2} \mathrm{O}_{3}+\mathrm{MEPCM}\right.$ and $\left.\mathrm{Cu}+\mathrm{MEPCM}\right)$ nanoparticles flowing in a micro-channel have been investigated by Hasan et al. [31]. The numerical study proved that increasing the concentration of nanoparticles improved the thermal performance of the micro-channel, but the study indicated that this improvement was accompanied by an obstacle of pressure drop. Acharya [32] investigated experimentally plus simulated data the effect of solar radiation on the heat transfer behavior and flow patterns of microchannels. $\mathrm{Al}_{2} \mathrm{O}_{3}-\mathrm{CuO}$ nanoparticles and their hybrid with water as the working fluid are considered. The numerical and experimental study showed that both nanofluid and hybrid nanofluid helped to enhance the heat transfer dramatically. Moreover, the study showed that the hybrid nanofluid has a higher heat transfer rate than the nanofluids.

It can be concluded that the previous studies have shown that microchannels with hybrid nanofluids have a major role in cooling small applications, especially electronic applications. Due to the importance of this topic, this study sought to develop this type of micro-channels with corrugated walls and hybrid nanofluid to keep pace with the technological development of electronic applications to find a satisfactory design for these applications. In this study, the laminar flow in the triangle microchannel with the trapezoidal corrugated surface is numerically studied. Microchannel with a trapezoidal-corrugated surface and hybrid nanofluid as a working fluid has not been studied previously according to the authors' information. The results of this numerical study could lead to an improved microchannel design used to cool systems for electronic devices.

\section{MATHEMATICAL FORMULATION}

\subsection{MCHS model and boundary conditions}

Figure 1 displays the geometries and Table 1 shows the main dimensions of the triangle micro-channel made from aluminum. All the surfaces of the micro-corrugated channel are completely isolated, except for the corrugated surface, where it is exposed to a heat flux of $25000 \mathrm{~W} / \mathrm{m}^{2}$. The temperature of the fluid entering the microchannel was $298 \mathrm{~K}$. The flowing fluid in the channel is a hybrid nanofluid composed of water and two different types of nanoparticles, namely $\mathrm{CuO}$ and $\mathrm{Ag} .80 \%$ of $\mathrm{CuO}$ and $20 \%$ of $\mathrm{Ag}$ were mixed in water to synthesis the $\mathrm{CuO}-\mathrm{Ag} /$ water hybrid nanofluid in this study. All physical and thermal properties of water and nanofluid are listed in Table 2.

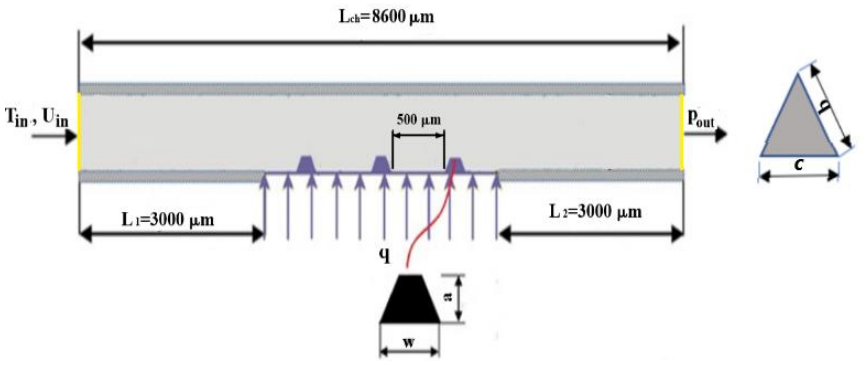

Figure 1. Schematic diagram of the numerical domain

Table 1. Dimensions of the triangular cross-section MCHS

\begin{tabular}{cccccccc}
\hline $\begin{array}{c}\mathbf{L}_{\mathrm{ch}} \\
(\boldsymbol{\mu \mathbf { m }})\end{array}$ & $\begin{array}{c}\mathbf{L}_{1} \\
(\boldsymbol{\mu \mathbf { m }})\end{array}$ & $\begin{array}{c}\mathbf{L}_{2} \\
(\boldsymbol{\mu \mathbf { m }})\end{array}$ & $\begin{array}{c}\mathbf{c} \\
(\boldsymbol{\mu \mathbf { m }})\end{array}$ & $\begin{array}{c}\mathbf{b} \\
(\boldsymbol{\mu \mathbf { m }})\end{array}$ & $\begin{array}{c}\mathbf{w} \\
(\boldsymbol{\mu \mathbf { m }})\end{array}$ & $\begin{array}{c}\mathbf{a} \\
(\boldsymbol{\mu \mathbf { m }})\end{array}$ & $\begin{array}{c}\mathbf{D}_{\mathbf{h}} \\
(\boldsymbol{\mu} \mathbf{m})\end{array}$ \\
\hline 8600 & 3000 & 3000 & 430 & 452 & 280 & $\begin{array}{c}50- \\
150\end{array}$ & 230 \\
\hline
\end{tabular}

\subsection{Governing equations}

\subsubsection{Single-phase model}

In the current numerical study, a set of hypotheses was adopted to achieve the final form of the governing equations. The flow is adopted to be steady-state conditions and threedimensional, the nanofluid and hybrid nanofluid are Newtonian and incompressible. Furthermore, the nanoparticles are assumed to be spherical and thermophysical properties of nanoparticles $(\mathrm{CuO}, \mathrm{Ag}$, and $\mathrm{CuO}-\mathrm{g})$ are Constant. In this model, it is possible to assume that the mixture is a homogeneous state when the nanoparticles are mixed with base fluid and they flow at the same velocity. Accordingly, the governing equations and the turbulent model for nanofluid and hybrid nanofluid flow can be written as [33]:

Continuity equation:

$$
\nabla \cdot\left(\rho_{n f} \cdot v_{m}\right)=0
$$

Momentum equation:

$$
\nabla \cdot\left(\rho_{n f} v_{m} \cdot v_{M}\right)=-\nabla P+\nabla \cdot\left(\mu_{n f} \cdot \nabla v_{m}\right)
$$

Energy equation:

$$
\nabla \cdot\left(\rho_{n f} \cdot C_{p_{n f}} \cdot v_{m} \cdot T\right)=\nabla \cdot\left(k_{n f} \cdot \nabla T\right)
$$

2.2.2 Hybrid nanofluid and nanofluid thermophysical properties

Since the thermophysical properties of nanofluids are not precisely estimated up to date. The numerical predictions of the single-phase model are generally not in good agreement with experimental results. Recently, researchers have studied the convection heat transfer with nanofluids using single- and two-phase model approaches. Many investigations have been performed on nanofluids considering the single-phase model due to its simplicity and short computational time requirement. To specify properties of nanofluid and hybrid nanofluid some experimental results have allowed using appropriate classical models that were derived from a single-phase mixture. The density and specific heat capacity of the $\mathrm{CuO} /$ water and $\mathrm{CuO}$ $\mathrm{Ag} /$ water hybrid nanofluid can be computed using the equations below: 


$$
\rho_{n f}=\phi_{p} \rho_{p}+\left(1-\phi_{p}\right) \rho_{b f}
$$

Eq. (4) was initially presented in Ref. [34] and then extensively used in works [34-38]. For specifying the density of hybrid nanofluid the equation below was used:

$$
\rho_{\text {hnf }}=\phi_{\text {CuO }} \rho_{\text {CuO }}+\phi_{A g} \rho_{A g}+(1-\phi) \rho_{b f}
$$

Eq. (6) was used to specify the overall volume concentration $(\phi)$ of two variable types of nanoparticles dispersed in the base fluid as:

$$
\phi=\phi_{C u O}+\phi_{A g}
$$

First employing the specific heat was in Ref. [39] then utilized in several kinds of research [33, 34, 40]:

$$
C_{n f}=\frac{\phi_{p} \rho_{p} C_{p}+\left(1-\phi_{p}\right) \rho_{b f} C_{b f}}{\rho_{n f}}
$$

Referring to (7), the specific heat of hybrid nanofluid has been calculated as the following:

$$
\begin{aligned}
& C_{\text {hnf }} \\
& =\frac{\phi_{C u O} \rho_{C u O} C_{C u O}+\phi_{\mathrm{Ag}} \rho_{\mathrm{Ag}} C_{M g O}+(1-\phi) \rho_{b f} C_{b f}}{\rho_{\text {hnf }}}
\end{aligned}
$$

Hamilton and Crosser [41] proposed the Eq. (9) to determine the thermal conductivity of nanofluids as:

$$
\begin{aligned}
& \frac{k_{n f}}{k_{b f}} \\
& =\frac{k_{P}+(n-1) k_{b f}-(n-1) \phi_{p}\left(k_{b f}-k_{p}\right)}{k_{p}+(n-1) k_{b f}+\phi_{p}\left(k_{b f}-k_{p}\right)}
\end{aligned}
$$

where, $n$ is the experimental profile factoring which is diverse from 0.5 to 6 and $\psi$ is the spherical particle factor which refers to the spherical surface area to the particle surface area. The experimental shape factor $n$ is specified by $3 / \psi$. Therefore, Hamilton and Crosser's model specified $n$ equals to 3 for spherical nanoparticles and it was similar to the Maxwell model [42]:

$$
\frac{\mathrm{k}_{\mathrm{nf}}}{\mathrm{k}_{\mathrm{bf}}}=\frac{\mathrm{k}_{\mathrm{p}}+2 \mathrm{k}_{\mathrm{bf}}-2 \phi_{\mathrm{p}}\left(\mathrm{k}_{\mathrm{bf}}-\mathrm{k}_{\mathrm{p}}\right)}{\mathrm{k}_{\mathrm{p}}+2 \mathrm{k}_{\mathrm{bf}}+\phi_{\mathrm{p}}\left(\mathrm{k}_{\mathrm{bf}}-\mathrm{k}_{\mathrm{p}}\right)}
$$

To find the most suitable model of thermal conductivity of nanofluid and hybrid nanofluid in varied volume concentrations. A comparison between Hamilton and Crosser [41], Corcione empirical correlation [43] which is derived from a wide variety of experimental data available in the literature, and Suresh experimental results [44] were made. It can be seen from Figure 2 the Maxwell models might not accurate to evaluate thermal conductivity, especially when nanoparticles concentration is high in the base fluid. Indeed, It was found that the Corcione empirical correlation [43] is slightly identical to the results of [44]. Accordingly, the Corcione empirical correlation [43] with the standard error deviation of $1.86 \%$ appears to be suitable to use in this study.

The empirical correlation of Corcione [43]:

$$
\frac{k_{n f}}{k_{b f}}=1+4.4 \operatorname{Re}^{0.4} \operatorname{Pr}^{0.66}\left(\frac{T}{T_{f r}}\right)^{10}\left(\frac{k_{p}}{k_{b f}}\right)^{0.03} \phi^{0.66}
$$

For the hybrid nanofluid:

$$
\frac{k_{n f}}{k_{b f}}=1+4.4 \operatorname{Re}^{0.4} \operatorname{Pr}^{0.66}\left(\frac{T}{T_{f r}}\right)^{10}\left(\frac{\frac{\left(\phi_{C u o} k_{C u O}+\phi_{\mathrm{Ag}} k_{\mathrm{Ag}}\right)}{\phi}}{k_{b f}}\right)^{0.03} \phi^{0.66}
$$

where, Re is the Reynolds number of nanoparticles, $\mathrm{P} r$ is the base fluid Prandtl number, $\mathrm{T}$ is the temperature of nanofluid, $\mathrm{T}_{f r}$ is the base liquid freezing point, $\mathrm{k}_{p}$ is the thermal conductivity of nanoparticle, and $\phi$ is the suspended nanoparticles volume fraction. In more detail, the nanoparticle Reynolds number is defined as:

$$
R e=\frac{\rho_{b f} u_{B} d_{p}}{\mu_{b f}}
$$

where, $\rho_{b f}$ is the mass density and $\mu_{b f}$ is the dynamic viscosity of the base fluid. and $\mathrm{d} p$ and $u_{\mathrm{B}}$ are the nanoparticle diameter and mean Brownian velocity, respectively. Assuming the absence of agglomeration, the nanoparticle Brownian velocity $u_{\mathrm{B}}$ is calculated as:

$$
u_{B}=\frac{2 k_{b f} T}{\pi \mu_{b f} d_{p}^{2}}
$$

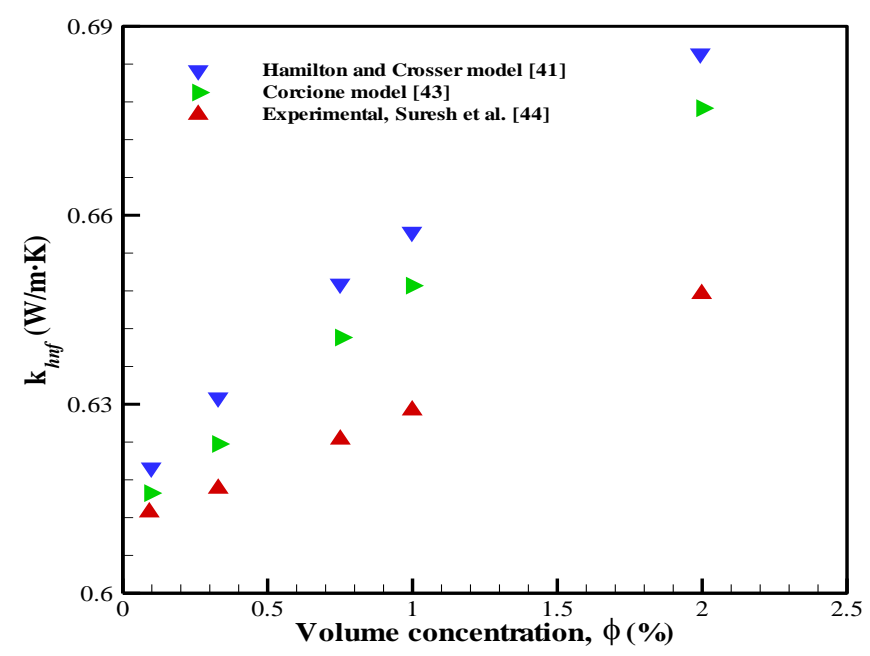

Figure 2. Thermal conductivity of $\mathrm{Al}_{2} \mathrm{O}_{3}-\mathrm{Cu}$ /water hybrid nanofluid at varied volume concentrations

Another most important property that plays an important role in improving heat transfer is viscosity. It may be noted through previous studies that most of the equations which were suggested by the practical experiments cannot be applied to infer the viscosity of nanofluids.

In this paper. Three models have been compared with an experimental study of Suresh [44] to find the most appropriate model to predict the viscosity of nanofluid and hybrid nanofluid. These models are listed below.

Brinkman model [45]:

$$
\mu_{n f}=\frac{\mu_{b f}}{(1-\phi)^{2.5}}
$$


Batchelor model [45]:

$$
\mu_{n f}=\mu_{b f}\left(1+K_{1} \phi+K_{2} \phi^{2}\right)
$$

where, $K_{1}$ is $2.5, K_{2}$ is considered as [44].

Corcione experimental correlation [43]:

$$
\mu_{n f}=\left[\frac{1}{1-34.87\left(\frac{d_{p}}{d_{b f}}\right)^{-0.3} \phi_{p}^{1.03}}\right] \mu_{b f}
$$

where,

$$
d_{b f=0.1\left(\frac{6 M}{N \pi \rho_{b f}}\right)^{0.33}}
$$

where,

M: Molecular weight of water, $(\mathrm{kg} / \mathrm{mol})=1.80 \mathrm{E}-02$.

$\mathrm{N}$ : Avogadro number, $(1 / \mathrm{mol})=6.02 E+23$.

By observing Figure 3, the classical models do not give very accurate values for the viscosity of hybrid nanofluid and nanofluid, especially in high-nanoparticle concentrations while Corcione's experimental correlation [43] is almost close to Suresh et al. [44] results. Accordingly, for high accuracy in this work, the Corcione experimental correlation [43] was used to obtain a nanofluid and hybrid nanofluid viscosity.

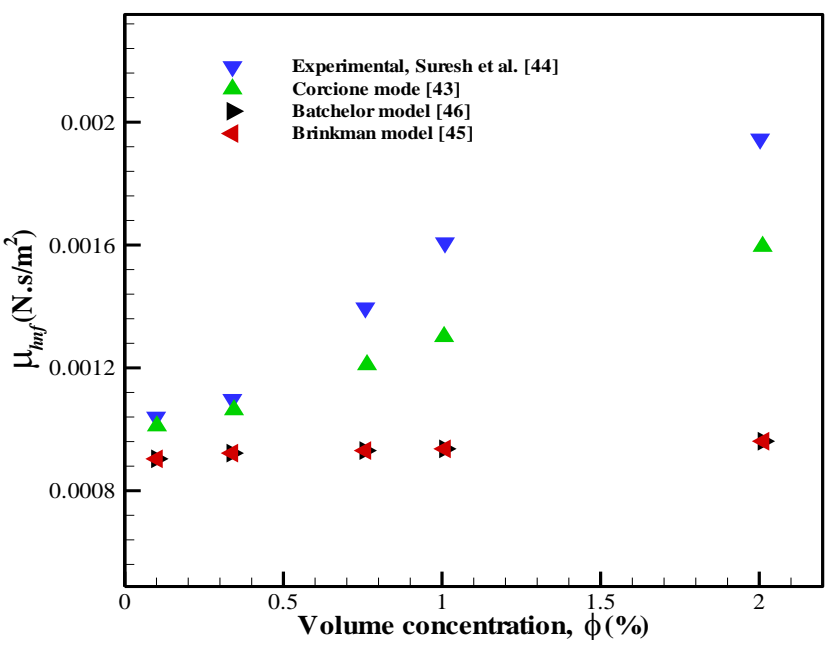

Figure 3. Dynamic viscosity of $\mathrm{Al}_{2} \mathrm{O}_{3}-\mathrm{Cu}$ /water hybrid nanofluid at varied volume concentrations

The thermophysical properties for all types of nanoparticles, base fluid (water), and the nanofluids with particle volume fraction of $2 \%$ are listed in Table 2. For all types of nanofluids, the density, thermal conductivity, and dynamic viscosity appear significantly higher while the specific heat of nanofluids is lower than pure water. Accordingly, the thermophysical properties of nanoparticles, base fluid, nanofluid, and hybrid nanofluid can be written as in Table 2.

Table 2. The thermophysical properties of nanoparticle, base fluid, nanofluid, and hybrid nanofluid at $293 \mathrm{~K}$

\begin{tabular}{lcccccc}
\hline Properties & Water & $\mathbf{C u O}$ & Ag & CuO-water $\boldsymbol{\phi = 2 \%}$ & Ag-water $\boldsymbol{\phi}=\mathbf{2 \%}$ & $\mathbf{C u O - A g / w a t e r ~} \boldsymbol{\phi}=\mathbf{2 \%}$ \\
\hline $\boldsymbol{\rho}\left(\mathbf{K g} / \mathbf{m}^{\mathbf{3}}\right)$ & 998.2 & 6500 & 10500 & 1108.236 & 1188.236 & 1124.236 \\
$\boldsymbol{C} \boldsymbol{p}(\boldsymbol{J} / \mathbf{k g} \boldsymbol{K})$ & 4182 & 535.6 & 235 & 3754.264 & 3611.684 & 3724.125 \\
$\boldsymbol{K}(\boldsymbol{W} / \mathbf{m} . \boldsymbol{K})$ & 0.613 & 20 & 429 & 0.654 & 0.662 & 0.65771 \\
$\boldsymbol{\mu} \boldsymbol{k g} / \boldsymbol{m} . \boldsymbol{s}$ & 0.001003 & & & 0.001237 & 0.001237 & 0.001237 \\
\hline
\end{tabular}

\section{GRID INDEPENDENCE TEST}

In this study, an unstructured grid was adopted in the computational domain with the addition of the number of layers on the walls of the channel as displayed in Figure 4. The grid independence test was done at Reynolds number of 100 with pure water. the element size has been changed from 13 to $20 \mu \mathrm{m}$ to show its impact on the values of the average Nusselt number as shown in Table 3 and Figure 5. It can be seen that this change of the element size did not have a significant effect on the change of Nusselt number values. Therefore, an element size of $15 \mu \mathrm{m}$ was adopted in this numerical study.

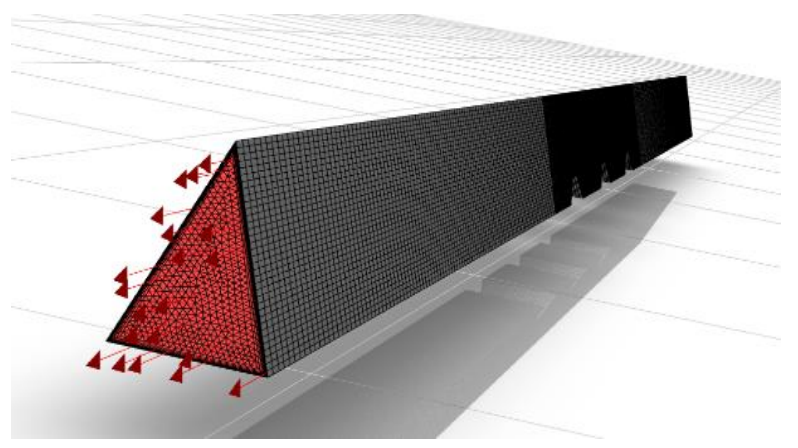

Figure 4. Unstructured mesh for the computational domain
Table 3. Mesh independence test for triangle microchannel at $(\mathrm{Re}=100)$

\begin{tabular}{ccc}
\hline Element size $(\boldsymbol{\mu m})$ & Number of elements & Nu \\
\hline 20 & 323872 & 6.197984 \\
18 & 395304 & 6.190576 \\
15 & 554212 & 6.152965 \\
13 & 694680 & 6.134159 \\
\hline
\end{tabular}

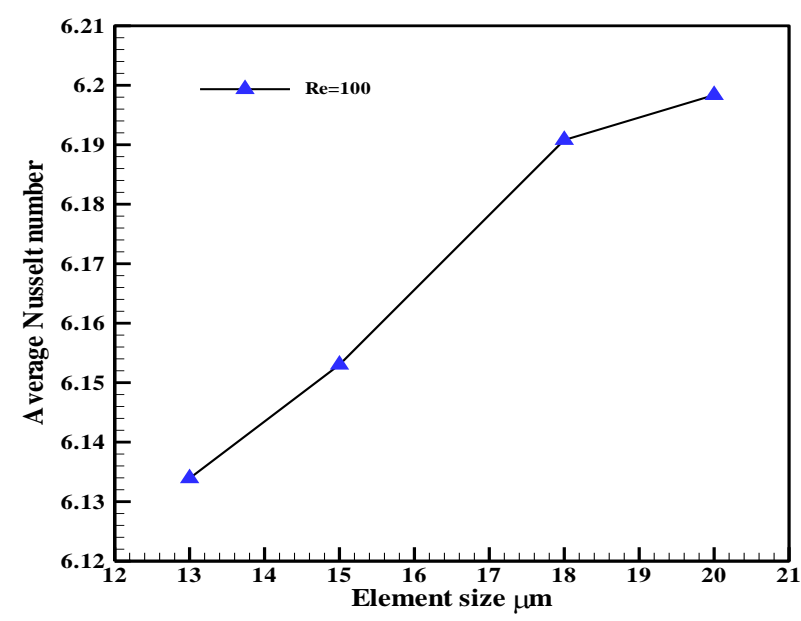

Figure 5. Grid independence test for laminar flow regime 


\section{NUMERICAL VALIDATION}

In order to obtain an accurate numerical method for the current study, initially, the simulation results have been compared with the studies $[46,47]$ at identical geometric and boundary conditions. Figure $6 \mathrm{a}$ shows the influence of $\mathrm{Al}_{2} \mathrm{O}_{3} /$ water nanofluid at different nanoparticle volume fractions and a rough rib of a rectangular microchannel on the average Nusselt number. Figure 6a shows a good agreement of current study results and reference results $[46,47]$.
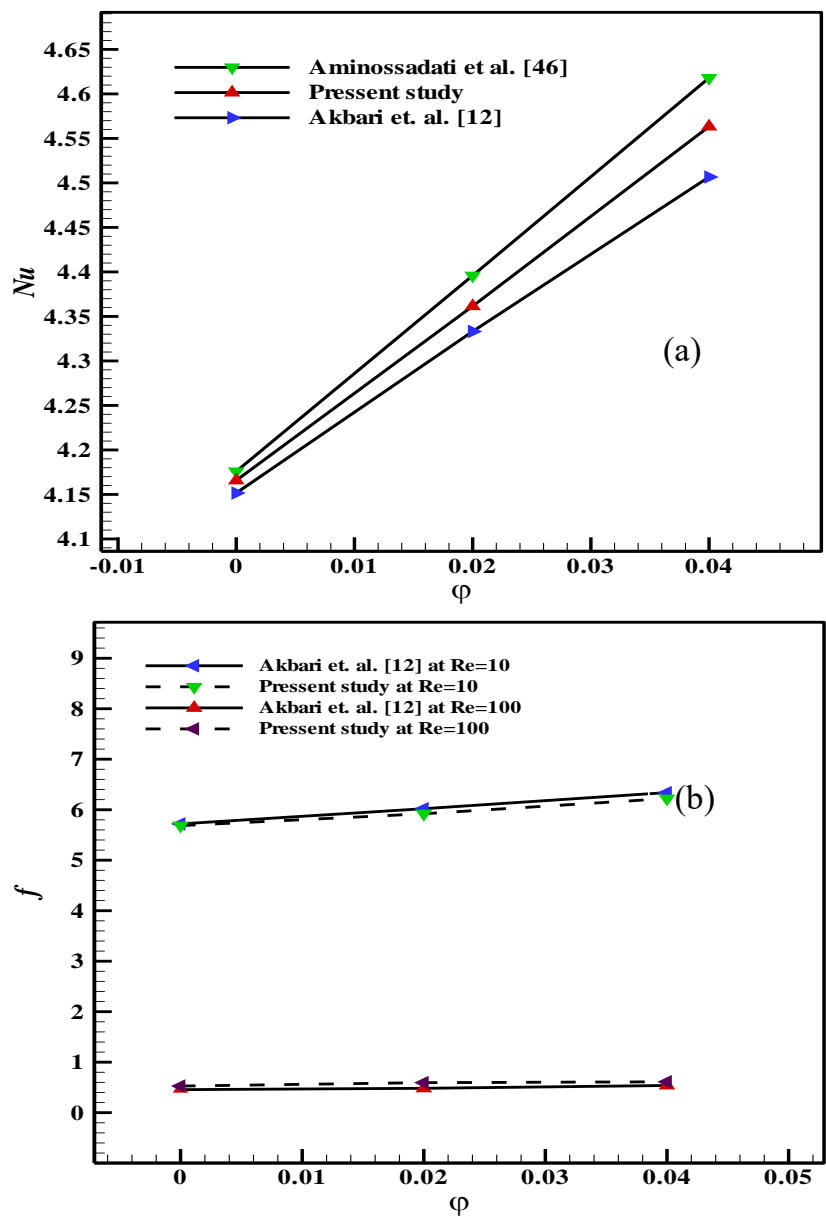

Figure 6. Comparison of current simulation work and the results of studies Aminossadati et al. [46], Akbari et al. [47]

The experimental work [48] has been chosen also to validate the results of the current work. Figure $6 b$ demonstrated the effect of the different nanoparticles concentration of $\mathrm{Al}_{2} \mathrm{O}_{3}$ / water nanofluid on the friction factor in a micro rectangular channel at Reynolds numbers of 10 and
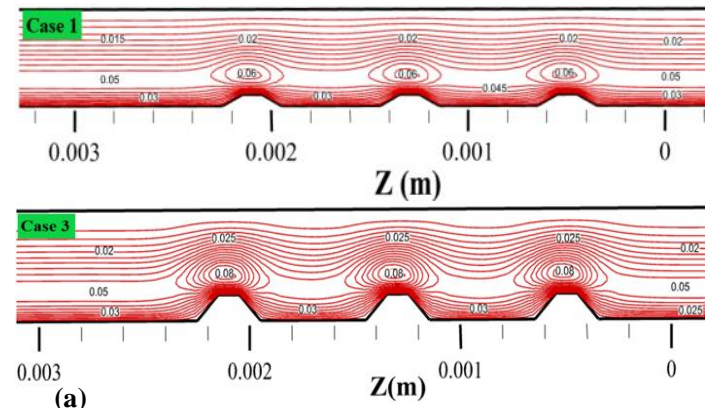

100 was studied. The numerical results of the current study showed a significant match with the results of the experimental study [48].

\section{RESULTS AND DISCUSSION}

The current study seeks to improve heat transfer through a triangular microchannel at a Reynolds number in the range of 5 to 500. This channel could be used to cool a surface with heat flux up to $25,000 \mathrm{~W} / \mathrm{m}^{2}$.

The improving heat transfer in the triangular microchannel relied mainly on two passive techniques, the first technique is by improving the surface of the channel that touches the hot part, while the second has adopted the improvement of thermal connectivity of the cooling fluid. In the first part of the study, the effect of the trapezoidal corrugated surface of the triangular microchannel on heat transfer was investigated numerically. Further clarification, wave amplitude has a significant effect on improving heat transfer and pressure losses, so it was considered in this study.

\subsection{Effects of wave amplitude on velocity streamlines}

Figure 7 shows a study of streamlines contours for water for the four cases, each case representing a certain wave height at Reynolds values ranging from 5 to 500 . The four cases $1,2,3$ and 4 gradually represented wave amplitude of 50, 75, 100, and $125 \mu \mathrm{m}$ respectively. Part a of Figure 7 represents the study of the effect of cases 1,2,3 and 4 at Reynolds 5. It is noted through Figure $7 \mathrm{a}$ that the shape and amplitude heights of the waves have no significant effect on the behavior of streamlines except the regions of the crest of the wave where the velocity increases slightly due to the convergence between the top of the wave and the upper wall which indicates that the rate of improvement in heat transfer is low. Moreover, Figure 7a shows that the velocity of the flow increases with the increase in the amplitude of the wave. Furthermore, Figure $7 \mathrm{~b}$ shows the streamlines at Reynolds number of 100 and amplitudes ranging from 50 to $125 \mu \mathrm{m}$. It should be noted from this Figure that the streamlines began to change in shape, especially at the wave amplitude of $125 \mu \mathrm{m}$, where the fluid has a normal velocity component and small vortexes began to form in the regions behind the peaks of the waves. This behavior increases significantly at Reynolds 500 as shown in Figure $7 \mathrm{c}$, as transverse vortices are formed in all the divergent areas. In this case, the heat transfer is at the highest level as a result of good mixing between the layers of hot fluid on the side of the hot wall and the layers of cold fluid in the core of the channel, where the vortices play a prominent role.
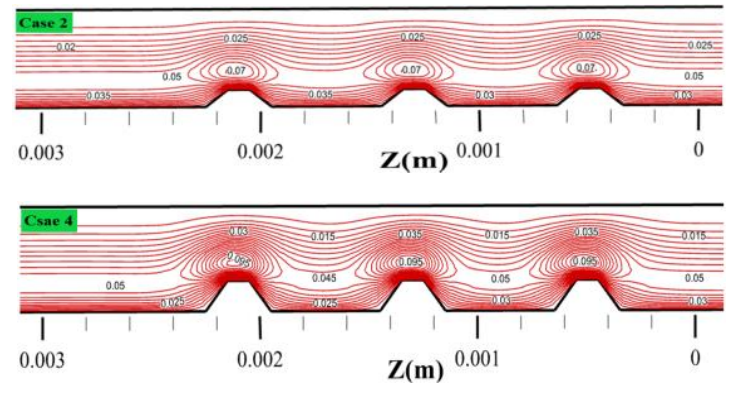

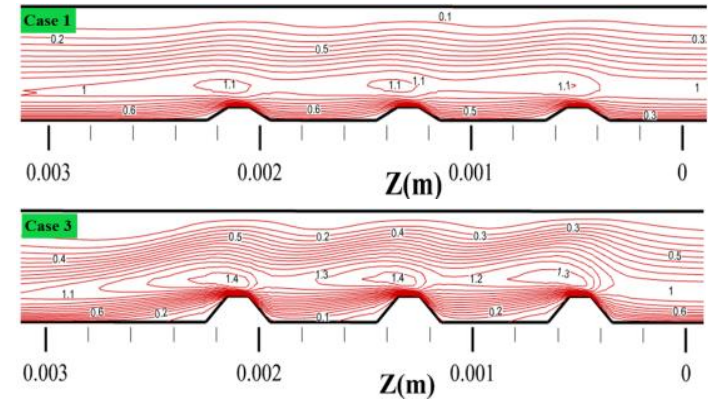

(b)
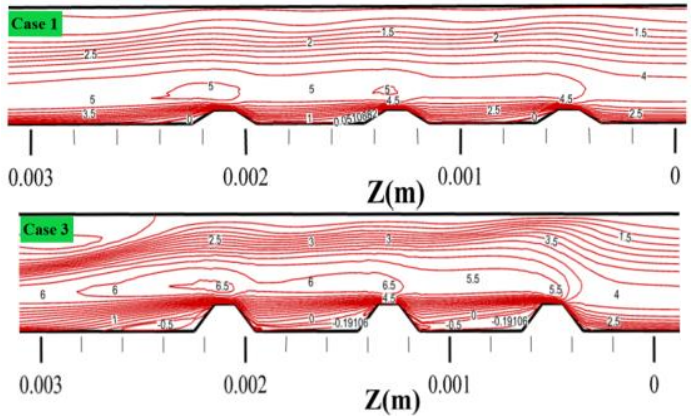

(c)
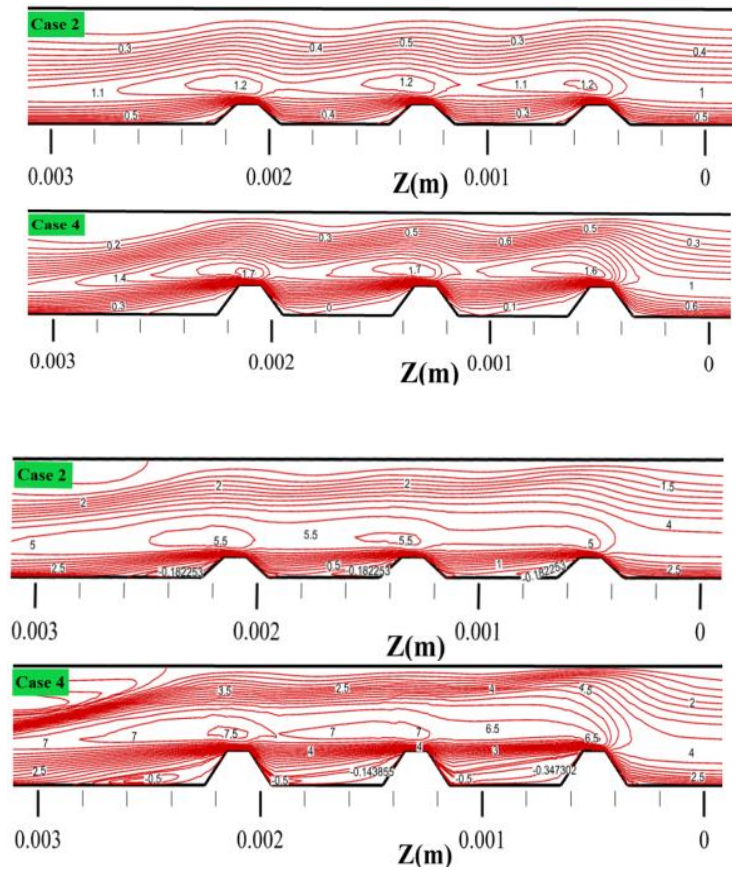

Figure 7. Streamlines contour of water for cases $1,2,3$ and 4 at Reynolds values of $a=5, b=100$, and $c=500$

\subsection{Effects of corrugated shapes on local Nusselt number and temperature distribution}

Figure 8 shows the distribution of local Nusselt number and temperature distribution on the corrugated surface of the triangular microchannel of Case 4 at Reynolds numbers 5, 100, and 500, and the heat flux on the corrugated wall was 25,000 $\mathrm{W} / \mathrm{m}^{2}$. Figure 8 shows that Re's increase has a significant impact on both local Nusselt number and temperature distribution, where a significant improvement in local Nusselt number is observed as the Reynolds number increases, while the opposite is evident in the decrease in temperature distribution at the corrugated surface as Reynolds number rise. Increased flow velocity usually helps to mix fluids well and thus reducing the temperature distribution, which leads to an improved heat transfer rate. Moreover, Figure 8 clearly shows that the corrugated surface has a significant effect on the local Nusselt number and the temperature distribution on the corrugated surface where it turns out that there are points along the surface of the corrugated wall the local Nusselt number is the highest value and for the points themselves the temperature distribution is at the lowest value. Due to the fact that the corrugated wall has created a high flow velocity in the convergent surface section while the values of the local Nusselt number have decreased and the temperature distribution value in the divergent section has increased due to the low flow velocity in this section. Moreover, when $\mathrm{Re}=5$, there is an obvious difference in the variation pattern of surface temperature. This is due to the fact that when $\mathrm{Re}=5$ the liquid particles remain trapped or have slow motion inside the divergent section and will not mix with the surrounding liquid, this may create an extremely hot area as well as a decrease in the velocity beyond the crest of the corrugated surfaces. Low flow velocity along the wall contributes to an increase in the thickness of the thermal boundary layer. In addition, Figure 8a shows that there is a noticeable rise in the value of the local Nusselt number on the surface of the first wave at the Reynolds number of 500, then it decreases after passing the sharp corner and then goes back up to the maximum value. This can be attributed to the separation of the flow at the sharp edge of the wave where the fluid is often no longer able to follow the profile of the shape because of its high velocity.

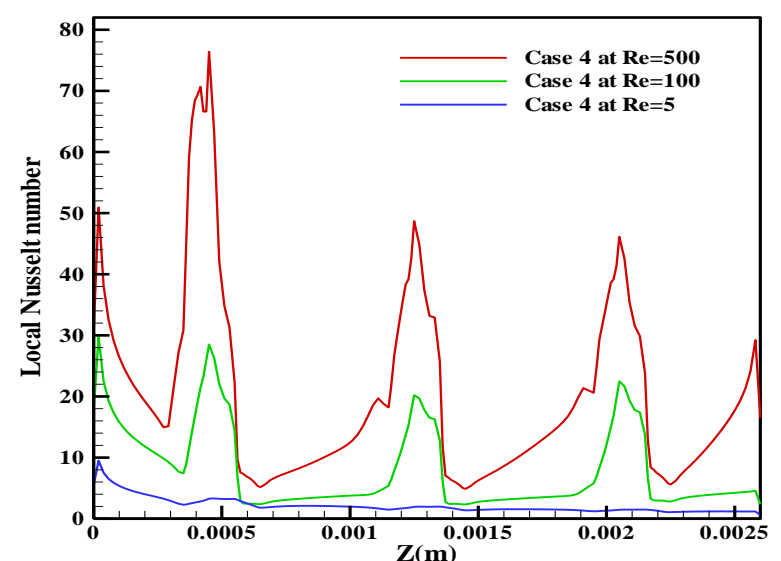

(a)

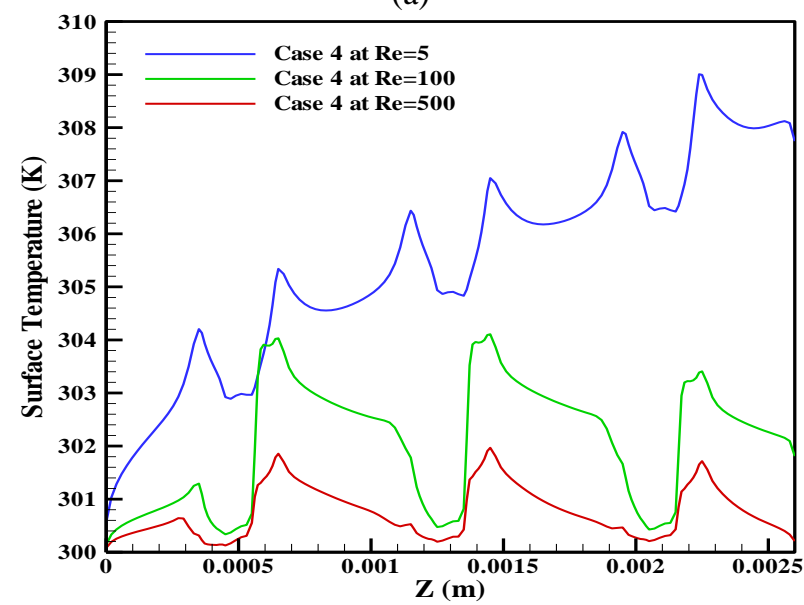

(b)

Figure 8. Distribution of local Nusselt number and temperature distribution of Case 4 at Reynolds numbers 5, 100 , and 500 


\subsection{Effects of corrugated shapes on average Nusselt number}

Figure 9 shows the average Nusselt number at Reynolds numbers 5, 100, and 500 for different cases of amplitude heights of the corrugated trapezoidal wall. The values of the average Nusselt number are gradually increasing with the increase in the Reynolds number and for all the cases due to the fact that the high velocity of flow usually increases the temperature gradient on the hot surfaces. Figure 9. also shows that average Nusselt number values were not significantly affected by the change of amplitude heights of the corrugated surface at Reynold number values less than 100 . This may be attributed to the fact that the shape of the flow profile has not changed significantly as a result of the change of the corrugated surface at low velocity because it followed the shape of the corrugated surface. On the contrary, it is clearly seen from Figure 9 that average Nusselt numbers have increased significantly as the wave amplitude increased at $\mathrm{Re}=500$, and as previously shown that the corrugated surface at high velocity formed vortices in the divergent section where these vortices significantly forced the cold water layers at the core of the microchannel to change direction to the hot water layers beside the hot wall and at the same time, the layers of hot water were forced to escape to the core of the channel, thereby gradually increasing the temperature gradients on the surface of the channel. In addition, the corrugated surfaces contribute to increased flow velocity in the converging section especially with increasing the wave amplitude, this action is similar to that of the nozzle in increasing the flow velocity in the converging section, therefore, the values of the Nusselt number in these sections are increased.

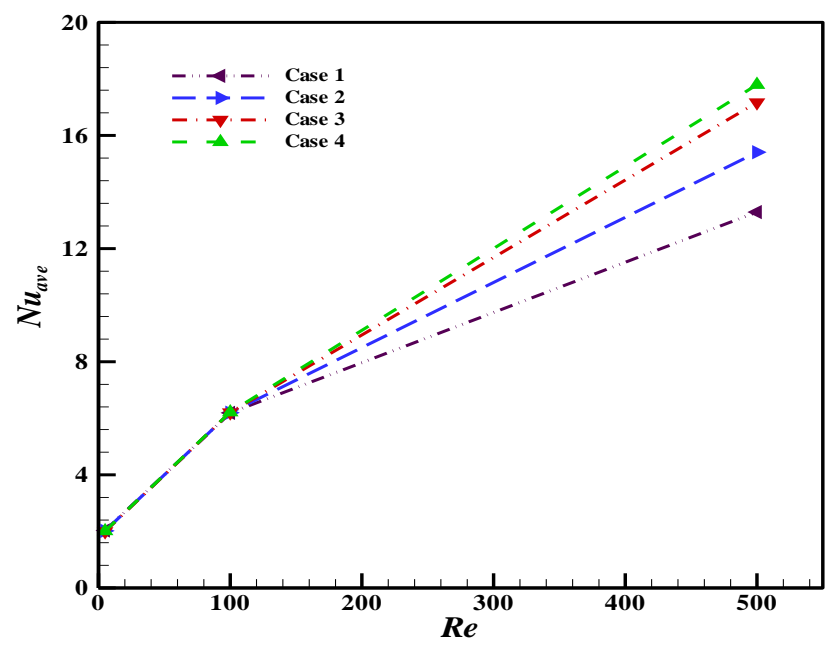

Figure 9. Average Nusselt number vs Reynolds numbers of 5,100 , and 500 of water at cases 1,2,3, and 4

\subsection{Effects of corrugated shapes on skin friction coefficient}

Figure 10 represents the effect of Reynold numbers of 5, 100, and 500 of water flow on the skin friction coefficient along the length of the microchannel for cases 1,2,3, and 4. It should be noted from Figure 10 that the values of the skin friction coefficient at $\mathrm{Re}=5$ for all cases are about 10 times higher than the skin friction coefficient at $\mathrm{Re}=100$. This can be explained by the fact that increased Reynolds numbers indicate that the highest flow velocity is in the core of the channel, which means that the highest amount of fluid will be in the core of the channel, and, conversely, the number of fluid molecules in contact with the walls will be very low, which means less skin friction. Also, low flow velocity means that fluid contact with walls will take longer, and therefore higher skin friction coefficient. Moreover, increasing the amplitude height of the corrugated wall also leads to more contact between the liquid and the walls which eventually causes an increase in the average skin friction coefficient of the walls.

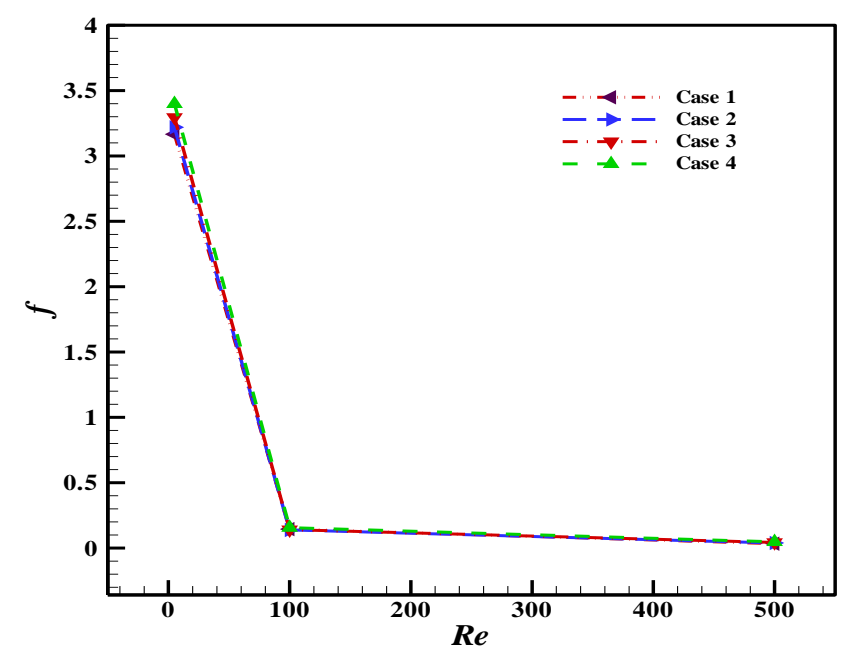

Figure 10. Skin friction coefficient vs Reynold number of 5, 100 , and 500 of water at cases 1,2,3, and 4

\subsection{Effect of base fluids, nanofluid, hybrid nanofluid on temperature distribution}

The effect of $2 \%$ nanoparticles concentration of $\mathrm{CuO} /$ water nanofluid, $\mathrm{Ag}$ water nanofluid, $\mathrm{CuO}-\mathrm{Ag} /$ water hybrid nanofluid flowing in the corrugated triangular microchannel with an amplitude of case 3 at $\mathrm{Re}=500$ on the temperature distribution has been investigated numerically. This effect on temperature distributions was compared with the case of water. Figure 11 shows through isothermal contour that the temperature distribution of $\mathrm{Ag} / \mathrm{water}$ nanofluid is less than the $\mathrm{CuO} /$ water nanofluid, $\mathrm{CuO}-\mathrm{Ag} /$ water hybrid nanofluid, and water due to the Brownian motion phenomenon and the thermal conductivity of the $\mathrm{Ag} /$ water nanofluid is higher than the thermal conductivity of $\mathrm{CuO} /$ water nanofluid, $\mathrm{CuO}$ $\mathrm{Ag} /$ water hybrid nanofluid, and water. The current study, as described earlier, aims to improve the thermal conductivity of $\mathrm{CuO} /$ water nanofluid by adding a small amount of nanoparticles with distinct properties than $\mathrm{CuO} /$ water nanofluid. First, Figure 11 showed that the temperature distribution in the case of $\mathrm{CuO}-\mathrm{Ag} /$ water hybrid nanofluid as working fluid is lower than the temperature distribution with $\mathrm{CuO}$ /water nanofluid, which means that the heat transfer by $\mathrm{CuO}-\mathrm{Ag} /$ water hybrid nanofluid is higher than $\mathrm{CuO} /$ water nanofluid.

Dispersed nanoparticles into the base fluid significantly improve heat transfer rate, where Macroscopic perspectives can describe this phenomenon. Nanoparticles in the liquid undergo irregular and random movements, caused by the concussion of the atoms and molecules that make up the liquid. It is also known that nanoparticles suspended in a liquid have a random motion called Brown motion where these particles hit the hot wall, which absorbs heat and then mixes with the bulk of the cold liquid again resulting in a decrease in the temperature of the hot wall. The macroscopic viewpoint 
proves that the addition of a simple quantity of nanoparticles to the base fluid improves the thermal properties of the fluid, especially when adding more than one type of nanoparticles.
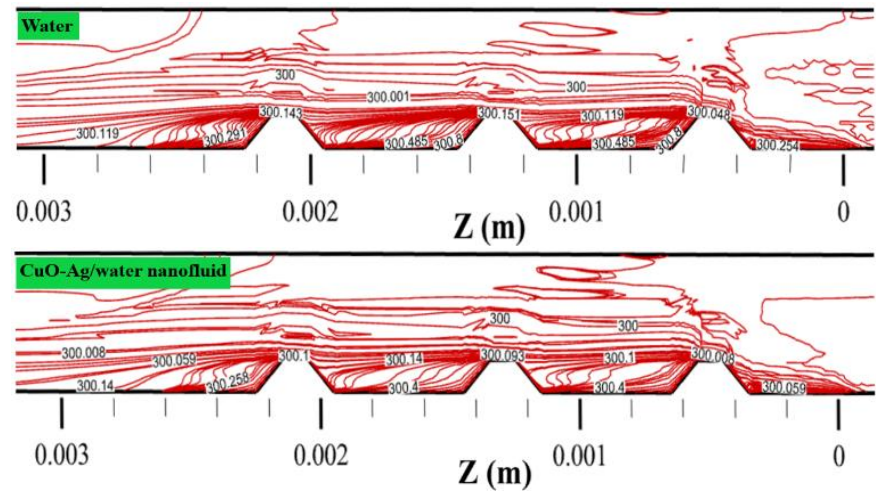

Figure 11. The isothermal contour of different nanofluids at $2 \%$ nanoparticles concentration and water for Case 3 at Reynolds number of 500

\subsection{Effect of base fluids nanofluid, hybrid nanofluid on average Nusselt number}

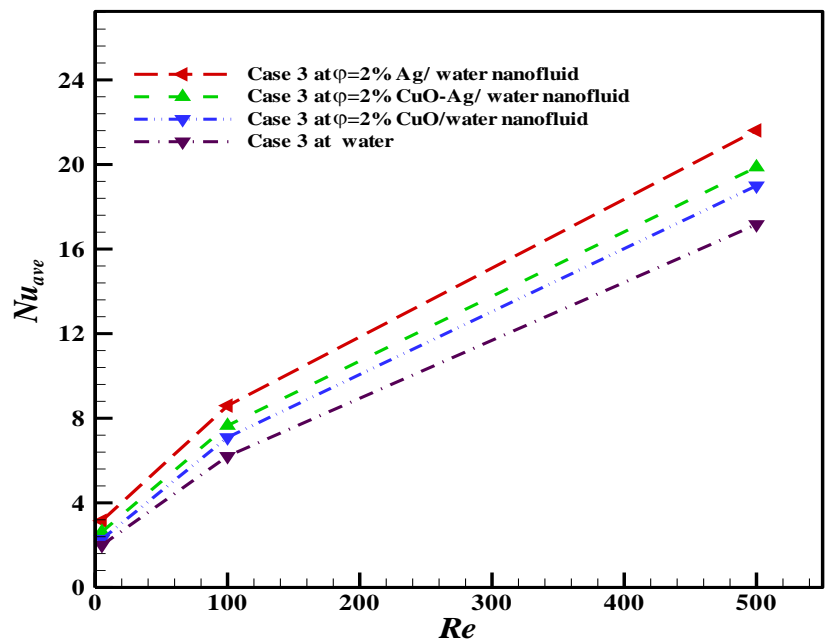

Figure 12. Average Nusselt number vs Reynolds number for different nanofluids at $2 \%$ nanoparticles concentration and water at Case 3

Figure 12 demonstrates the variation of the average Nusselt number with Reynolds number of $2 \%$ nanoparticles concentration of $\mathrm{CuO} /$ water nanofluid, $\mathrm{Ag}$ water nanofluid, $\mathrm{CuO}-\mathrm{Ag} /$ water hybrid nanofluid flowing in the corrugated triangular microchannel of Case 3 . It is found that the average Nusselt number increases with increasing Reynolds number for all the working fluids. This can be explained by the fact that the high flow rate leads to thinning of the thermal boundary layers, leading to lower thermal resistance and thus increased heat transfer rate. Furthermore, $\mathrm{Ag}$ / water nanofluid has the highest average Nusselt number followed by $\mathrm{CuO}$ $\mathrm{Ag} /$ water hybrid nanofluid, $\mathrm{CuO} /$ water nanofluid, and water. The reason for this is that the thermal conductivity of $\mathrm{Ag}$ nanofluid is higher than the thermal conductivity of $\mathrm{CuO}$ $\mathrm{Ag} /$ hybrid nanofluid and $\mathrm{CuO}$ nanofluid, and increasing Reynolds means increasing the velocity of flow, in other words, the velocity of nanoparticles will increase and their collision with hot walls and between them will increase, resulting in higher heat absorption, particularly with the $\mathrm{Ag}$ nanofluid because it has the highest thermal conductivity. Yet
Therefore, the heat transfer performance is positively affected by hybrid nanofluid because it leads to the improved thermal conductivity of the Nano-and conventional fluid.
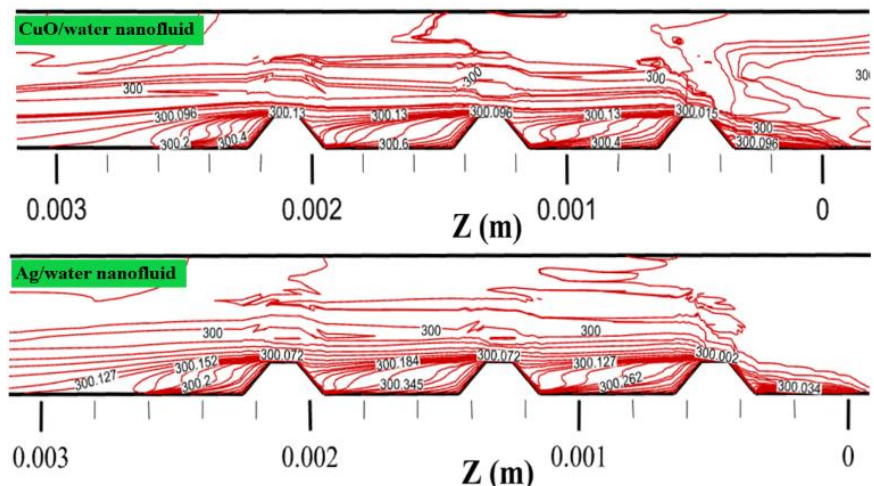


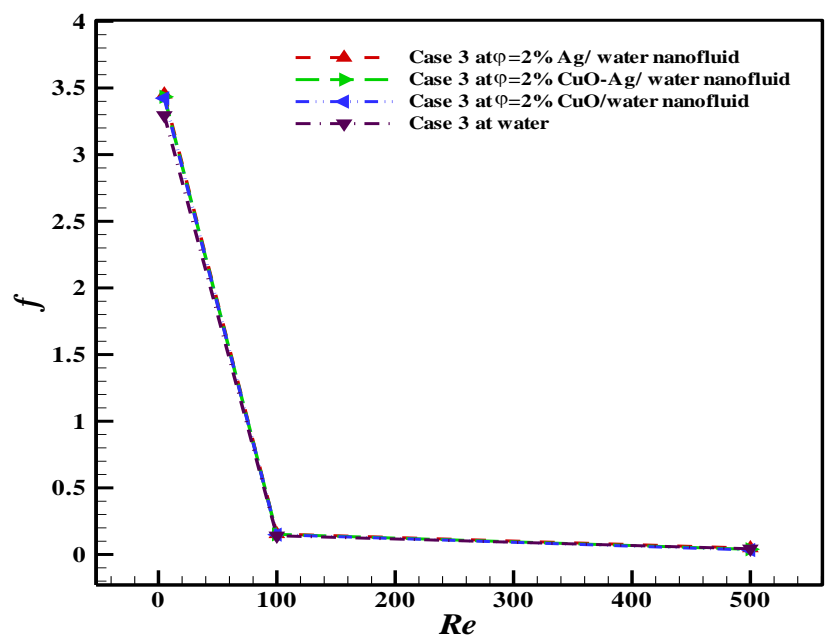

Figure 13. Skin friction coefficient vs Reynolds number for different nanofluids at $2 \%$ nanoparticles concentration and water at Case 3

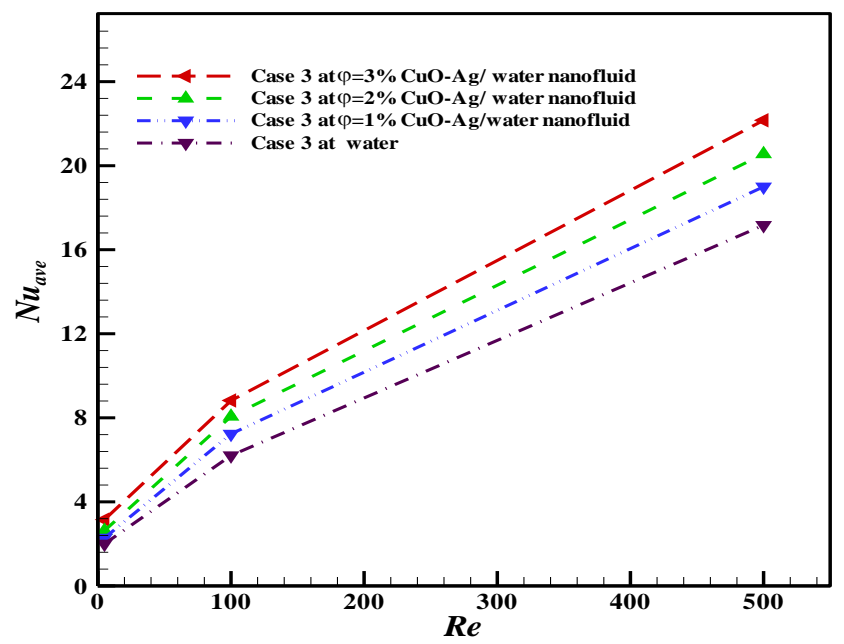

Figure 14. Average Nusselt number vs Reynolds number for different nanofluids at $\varphi=1,2$, and $3 \%$ nanoparticles concentration and water for Case 3

\section{CONCLUSION}

In the current study, the effect of different amplitude heights of a trapezoidal-corrugated wall in a triangular microchannel on thermal and hydraulic performance has been verified numerically. Four cases, 50, 75, 100, and $125 \mu \mathrm{m}$ represented the wave heights of the corrugated wall. The study also investigated the effect of adding a small amount of silver nanoparticles on the thermal conductivity of copper oxide nanofluid. Nanoparticles concentrations of 1,2, and 3\% of 80 copper oxide and $20 \%$ silver nanoparticles were also studied. The study was conducted at Reynolds 5, 100, and 500, and the corrugated surface was exposed to a constant heat flux of $25,000 \mathrm{~W} / \mathrm{m}^{2}$. The results of the study can therefore be summarized:

1. There is no interesting effect of changing the wave height of the corrugated wall on the velocity streamlines at Reynold number $=5$.

2. Increasing the flow velocity in the convergence regions as the wave height increases causes an increase in the local Nusselt number and a decrease in the surface temperature, whereas the opposite occurs in the divergence regions.

3. The skin friction coefficient at $\mathrm{Re}=5$ for all cases is about 10 times higher than the skin friction coefficient at $\mathrm{Re}=$ 100.

4. Incorporating a small amount of $\mathrm{Ag}$ nanoparticles into traditional nanofluid $\mathrm{CuO}$ /water has resulted in significant improvements in thermal connectivity while adding $\mathrm{Ag}$ nanoparticles to the traditional nanofluid $\mathrm{CuO}$ /water caused a higher skin friction coefficient.

5. Temperature distribution on the corrugated wall for the case of $\mathrm{Ag} /$ water nanofluid is less than the $\mathrm{CuO} /$ water nanofluid, $\mathrm{CuO}-\mathrm{Ag} /$ water hybrid nanofluid.

6. average Nusselt number increases as the volume fraction of nanoparticles of the hybrid nanofluid increase at a constant Reynolds number.

In general, the numerical results of the current study showed that using hybrid nanofluid instead of Nanofluid and traditional heat transfer fluids as well as using corrugated channels instead of the conventional (straight) channel can potentially achieve considerable improvement in the heat transfer performance, which can lead to design more compact heat exchangers.

\section{REFERENCES}

[1] Siddique, M., Khaled, A.R.A., Abdulhafiz, N.I., Boukhary, A.Y. (2010). Recent advances in heat transfer enhancements: A review report. Int. J. Chem. Eng., 2010: 106461. https://doi.org/10.1155/2010/106461

[2] Hung, T.C., Yan, W.M., Wang, X.D., Chang, C.Y. (2012). Heat transfer enhancement in microchannel heat sinks using nanofluids. International Journal of Heat and Mass Transfer, 55(9-10): 2559-2570. https://doi.org/10.1016/j.ijheatmasstransfer.2012.01.004

[3] Rezaei, O., Akbari, O.A., Marzban, A., Toghraie, D., Pourfattah, F., Mashayekhi, R. (2017). The numerical investigation of heat transfer and pressure drop of turbulent flow in a triangular microchannel. Physica E: Low-Dimensional Systems and Nanostructures, 931: 179-189. https://doi.org/10.1016/j.physe.2017.06.013

[4] Tiwari, A.K. Pandya, N.S., Said, Z., Öztop, H.F., AbuHamdeh, N. (2021). 4S consideration (synthesis, sonication, surfactant, stability) for the thermal conductivity of $\mathrm{CeO}_{2}$ with MWCNT and water-based hybrid nanofluid: An experimental assessment. Colloids and Surfaces A: Physicochemical and Engineering Aspects, $\quad 610$ : 125918. https://doi.org/10.1016/j.colsurfa.2020.125918

[5] Esfe, M.H., Behbahani, P.M., Arani, A.A.A., Sarlak, M.R. (2017). Thermal conductivity enhancement of $\mathrm{SiO}_{2}-$ MWCNT (85:15\%)-EG hybrid nanofluids: ANN designing, experimental investigation, cost performance, and sensitivity analysis. J. Therm. Anal. Calorim., 128: 249-258. https://doi.org/10.1007/s10973-016-5893-9

[6] Sajid, M.U., Ali, H.M. (2018). Thermal conductivity of hybrid nanofluids: A critical review. International Journal of Heat and Mass Transfer, 126: 211-234. https://doi.org/10.1016/j.ijheatmasstransfer.2018.05.021

[7] Esfe, M.H., Arani, A.A.A., Firouzi, M. (2017). Empirical study and model development of thermal conductivity improvement and assessment of cost and sensitivity of EG-water based SWCNT-ZnO (30\%:70\%) hybrid nanofluid. Journal of Molecular Liquids, 244: 252-261. 


\section{https://doi.org/10.1016/j.molliq.2017.08.087}

[8] Afrand, M. (2017). Experimental study on thermal conductivity of ethylene glycol containing hybrid nanoadditives and development of a new correlation. Applied Thermal Engineering, 110: 1111-1119. https://doi.org/10.1016/j.applthermaleng.2016.09.024

[9] Nfawa, S.R., Basri, A.A., Masuri, S.U. (2021). Novel use of $\mathrm{MgO}$ nanoparticle additive for enhancing the thermal conductivity of $\mathrm{CuO} /$ water nanofluid. Case Studies in Thermal Engineering, 27: 101279. https://doi.org/10.1016/j.csite.2021.101279

[10] Zhu, D.H., Wang, L.L., Yu, W., Xie, H.Q. (2018). Intriguingly high thermal conductivity increment for $\mathrm{CuO}$ nanowires contained nanofluids with low viscosity. Sci. Rep., 8: 5282. https://doi.org/10.1038/s41598-01823174-z

[11] Shah, J., Kumar, S., Ranjan, M., Sonvane, Y., Thareja, P., Gupta, S.K. (2018). The effect of filler geometry on thermo-optical and rheological properties of $\mathrm{CuO}$ nanofluid. Journal of Molecular Liquids, 272: 668-675. https://doi.org/10.1016/j.molliq.2018.09.117

[12] Wang, Y., Fisher, T., Davidson, J., Jiang, L. (2002). Thermal conductivity of nanoparticle suspensions. In 8th AIAA/ASME Joint Thermophysics and Heat Transfer Conference, p. 3345.

[13] Karimipour, A., Alipour, H., Akbari, O.A., Semiromi, D.T., Esfe, M.H. (2015). Studying the effect of indentation on flow parameters and slow heat transfer of water-silver nano-fluid with varying volume fraction in a rectangular two-dimensional microchannel. Indian J Sci Technol, 8(15): 51707. https://doi.org/10.17485/ijst/2015/v8i15/51707

[14] Safety, M., Goshayeshi, H. (2010). Numerical simulation of laminar and turbulent mixed convection in a rectangular enclosure with hot upper moving wall. ADMT J., 3(2).

[15] Bahiraei, M., Heshmatian, S. (2018). Thermal performance and second law characteristics of two new microchannel heat sinks operated with hybrid nanofluid containing graphene-silver nanoparticles. Energy Convers. $\quad$ Manag., 168 : 357-370. https://doi.org/10.1016/j.enconman.2018.05.020

[16] Khosravi, R., Rabiei, S., Bahiraei, M., Teymourtash, A.R. (2019). Predicting entropy generation of a hybrid nanofluid containing graphene-platinum nanoparticles through a microchannel liquid block using neural networks. Int. Commun. Heat Mass Transf., 109: 104351. https://doi.org/10.1016/j.icheatmasstransfer.2019.10435 1

[17] Safaei, M.R., Goodarzi, M., Goshayeshi, H.R. (2012). Numerical modeling of turbulence mixed convection of water and drilling mud inside a square enclosure by various turbulence models. https://dx.doi.org/10.22078/pr.2013.117

[18] Hilo, A., Talib, A.R.A., Nfawa, S.R., Sultan, M.T.H. (2018). Review of improvements on heat transfer using nanofluids via corrugated facing step. International Journal of Engineering \& Technology, 7(4): 160-169. https://doi.org/10.14419/ijet.v7i4.13.21350

[19] Nfawa, S.R., Masuri, S.U., Basri, A.A., Hasini, H. (2019). Heat transfer enhancement in a corrugated-trapezoidal channel using winglet vortex generators. CFD Letters, 10(10): 69-80.

[20] Karimipour, A., Nezhad, A.H., D’Orazio, A., Esfe, M.H.,
Safaei, M.R., Shirani, E. (2015). Simulation of copperwater nanofluid in a microchannel in slip flow regime using the lattice Boltzmann method. Eur. J. Mech., 49: 89-99.

https://doi.org/10.1016/j.euromechflu.2014.08.004

[21] Sarafraz, M.M., Yang, B., Pourmehran, O., Arjomandi, M., Ghomashchi, R. (2019). Fluid and heat transfer characteristics of aqueous graphene nanoplatelet (GNP) nanofluid in a microchannel. Int. Commun. Heat Mass Transf., 107: 24-33. https://doi.org/10.1016/j.icheatmasstransfer.2019.05.00 4

[22] Lyu, Z., Pourfattah, F., Arani, A.A.A., Asadi, A., Foong, L.K. (2020). On the thermal performance of a fractal microchannel subjected to water and kerosene carbon nanotube nanofluid. Sci. Rep., 10: 7243. https://doi.org/10.1038/s41598-020-64142-w

[23] Bahiraei, M., Jamshidmofid, M., Goodarzi, M. (2019). Efficacy of a hybrid nanofluid in a new microchannel heat sink equipped with both secondary channels and ribs. Journal of Molecular Liquids, 273: 88-98. https://doi.org/10.1016/j.molliq.2018.10.003

[24] Hosseini, S.R., Sheikholeslami, M., Ghasemian, M., Ganji, D.D. (2018). Nanofluid heat transfer analysis in a microchannel heat sink (MCHS) under the effect of magnetic field by means of KKL model. Powder Technol., 324: 36-47. https://doi.org/10.1016/j.powtec.2017.10.043

[25] Mashayekhi, R., Khodabandeh, E., Akbari, O.A., Toghraie, D., Bahiraei, M., Gholami, M. (2018). CFD analysis of thermal and hydrodynamic characteristics of hybrid nanofluid in a new designed sinusoidal doublelayered microchannel heat sink. Journal of Thermal Analysis and Calorimetry, 134(3): 2305-2315. https://doi.org/10.1007/s10973-018-7671-3

[26] Heidarshenas, A., Azizi, Z., Peyghambarzadeh, S.M., Sayyahi, S. (2021). Experimental investigation of heat transfer enhancement using ionic liquid $-\mathrm{Al}_{2} \mathrm{O}_{3}$ hybrid nanofluid in a cylindrical microchannel heat sink. Applied Thermal Engineering, 191: 116879. https://doi.org/10.1016/j.applthermaleng.2021.116879

[27] Rabiei, S., Khosravi, R., Bahiraei, M., Raziei, M., Hosseini, A.A. (2020). Thermal and hydraulic characteristics of a hybrid nanofluid containing graphene sheets decorated with platinum through a new wavy cylindrical microchannel. Appl. Therm. Eng., 181: 115981. https://doi.org/10.1016/j.applthermaleng.2020.115981

[28] Ghachem, K., Aich, W., Kolsi, L. (2021). Computational analysis of hybrid nanofluid enhanced heat transfer in cross flow micro heat exchanger with rectangular wavy channels. Case Stud. Therm. Eng., 24: 100822. https://doi.org/10.1016/j.csite.2020.100822

[29] Sarvar-Ardeh, S., Rafee, R., Rashidi, S. (2021). Hybrid nanofluids with temperature-dependent properties for use in double-layered microchannel heat sink; hydrothermal investigation. Journal of the Taiwan Institute of Chemical Engineers, 124: 53-62. https://doi.org/10.1016/j.jtice.2021.05.007

[30] Alnaqi, A.A., Alsarraf, J., Al-Rashed, A.A.A.A., Afrand, M. (2021). Thermal-hydraulic analysis and irreversibility of the MWCNTs-SiO $/$ EG- $\mathrm{H}_{2} \mathrm{O}$ non-Newtonian hybrid nanofluids inside a zigzag micro-channels heat sink. Int. Commun. Heat Mass Transf., 122: 105158. 
https://doi.org/10.1016/j.icheatmasstransfer.2021.10515 8

[31] Hasan, M.I., Khafeef, M.J., Mohammadi, O., Bhattacharyya, S., Issakhov, A. (2021). Investigation of counterflow microchannel heat exchanger with hybrid nanoparticles and PCM suspension as a coolant. Math. Probl. Eng., 2021: 6687064. https://doi.org/10.1155/2021/6687064

[32] Acharya, N. (2020). On the flow patterns and thermal behaviour of hybrid nanofluid flow inside a microchannel in presence of radiative solar energy. $\mathrm{J}$. Therm. Anal. Calorim., 141(4): 1425-1442. https://doi.org/10.1007/s10973-019-09111-w

[33] Moraveji, M.K., Ardehali, R.M. (2013). CFD modeling (comparing single and two-phase approaches) on thermal performance of $\mathrm{Al}_{2} \mathrm{O}_{3}$ /water nanofluid in mini-channel heat sink. Int. Commun. Heat Mass Transf., 44: 157-164. https://doi.org/10.1016/j.icheatmasstransfer.2013.02.01 2

[34] Pak, B.C., Cho, Y.I. (1998). Hydrodynamic and heat transfer study of dispersed fluids with submicron metallic oxide particles. Experimental Heat Transfer, 11(2):

151-170. https://doi.org/10.1080/08916159808946559

[35] Rostamani, M., Hosseinizadeh, S.F., Gorji, M., Khodadadi, J.M. (2010). Numerical study of turbulent forced convection flow of nanofluids in a long horizontal duct considering variable properties. Int. Commun. Heat Mass Transf., 37(10): 1426-1431. https://doi.org/10.1016/j.icheatmasstransfer.2010.08.00 7

[36] Bianco, V., Manca, O., Nardini, S. (2011). Numerical investigation on nanofluids turbulent convection heat transfer inside a circular tube. Int. J. Therm. Sci., 50(3): 341-349. https://doi.org/10.1016/j.ijthermalsci.2010.03.008

[37] Bianco, V., Manca, O., Nardini, S. (2010). Numerical simulation of water $/ \mathrm{Al}_{2} \mathrm{O}_{3}$ nanofluid turbulent convection. Adv. Mech. Eng., 2: 976254. https://doi.org/10.1155/2010/976254

[38] Ben-Mansour, R., Habib, M.A. (2013). Use of nanofluids for improved natural cooling of discretely heated cavities. Adv. Mech. $\quad$ Eng., 2013: 383267. https://doi.org/10.1155/2013/383267

[39] Kulkarni, D., Das, D.K., Patil, S. (2007). Effect of temperature on rheological properties of copper oxide nanoparticles dispersed in propylene glycol and water mixture. J. Nanosci. Nanotechnol., 7(7): 2318-2322. https://doi.org/10.1166/jnn.2007.437

[40] Bianco, V., Chiacchio, F., Manca, O., Nardini, S. (2009). Numerical investigation of nanofluids forced convection in circular tubes. Appl. Therm. Eng., 29(17-18): 36323642 . https://doi.org/10.1016/j.applthermaleng.2009.06.019

[41] Hamilton, R.L., Crosser, O.K. (1962). Thermal conductivity of heterogeneous two-component systems. Ind. Eng. Chem. Fundam., 1(3): 187-191. https://doi.org/10.1021/i160003a005

[42] Maxwell, J.C. (2010). A Treatise on Electricity and Magnetism, vol. 1. Clarendon Press.

[43] Corcione, M. (2011). Empirical correlating equations for predicting the effective thermal conductivity and dynamic viscosity of nanofluids. Energy Convers. Manag.,

52(1):

789-793. https://doi.org/10.1016/j.enconman.2010.06.072

[44] Suresh, S., Venkitaraj, K.P., Selvakumar, S., Chandrasekar, M. (2011). Synthesis of $\mathrm{Al}_{2} \mathrm{O}_{3}-\mathrm{Cu} /$ water hybrid nanofluids using two step method and its thermo physical properties. Colloids and Surfaces A: Physicochemical and Engineering Aspects, 388(1-3): 4148. https://doi.org/10.1016/j.colsurfa.2011.08.005

[45] Brinkman, H.C. (1952). The viscosity of concentrated suspensions and solutions. J. Chem. Phys., 20(4): 571. https://doi.org/10.1063/1.1700493

[46] Aminossadati, S.M., Raisi, A., Ghasemi, B. (2011). Effects of magnetic field on nanofluid forced convection in a partially heated microchannel. Int. J. Non. Linear. Mech., 46(10): 1373-1382. https://doi.org/10.1016/j.ijnonlinmec.2011.07.013

[47] Akbari, O.A., Toghraie, D., Karimipour, A. (2015). Impact of ribs on flow parameters and laminar heat transfer of water-aluminum oxide nanofluid with different nanoparticle volume fractions in a threedimensional rectangular microchannel. Adv. Mech. Eng., 7(11): 1-11. https://doi.org/10.1177/1687814015618155

[48] Saha, G. (2010). Finite element simulation of magnetoconvection inside a sinusoidal corrugated enclosure with discrete iso flux heating from below. Int. Commun. Heat Mass Transf., 37(4): 393-400. https://doi.org/10.1016/j.icheatmasstransfer.2009.12.00 1

[49] Hussain, S.H., Hussein, A.K., Mohammed, R.N. (2012). Studying the effects of a longitudinal magnetic field and discrete isoflux heat source size on natural convection inside a tilted sinusoidal corrugated enclosure. Comput. Math. with Appl., 64(4): 476-488. https://doi.org/10.1016/j.camwa.2011.12.022

[50] Khanafer, K., Vafai, K., Lightstone, M. (2003). Buoyancy-driven heat transfer enhancement in a twodimensional enclosure utilizing nanofluids. International Journal of Heat and Mass Transfer, 46(19): 3639-3653. https://doi.org/10.1016/S0017-9310(03)00156-X

\section{NOMENCLATURE}

$\begin{array}{ll}a & \text { Wave amplitude, } \mu \mathrm{m} \\ b, c & \text { Sides lengths of the Triangle, } \mu \mathrm{m} \\ C_{p} & \text { Specific heat capacity, J/kgK } \\ d p & \text { Nanoparticles dimeter } \\ D_{h} & \text { Hydraulic diameter, } \mu \mathrm{m} \\ f & \text { Skin friction factor } \\ k & \text { Thermal conductivity, W/mK } \\ L & \text { Length, } \mu \mathrm{m} \\ M & \text { Molecular weight, } \mathrm{kg} / \mathrm{mol} \\ N & \text { Avogadro number, } 1 / \mathrm{mol} \\ N u & \text { Nusselt number } \\ P r & \text { Prandtl number } \\ q & \text { Heat flux, w/m }{ }^{2} \\ R e & \text { Reynolds number } \\ T & \text { Temperature, K } \\ w & \text { Corrugated ribs base, } \mu \mathrm{m} \\ u_{\mathrm{B}} & \text { Brownian velocity } \\ v & \text { velocity, m/s }\end{array}$

\section{Greek symbols}

$\rho \quad$ Density, $\mathrm{kg} / \mathrm{m}^{3}$ 


$\begin{array}{ll}\phi & \text { Volume fraction } \\ \mu & \text { Dynamic viscosity, } \mathrm{kg} / \mathrm{m} . \mathrm{s} \\ \psi & \text { spherical particle factor }\end{array}$

Subscripts

$a v r$

average

$\begin{array}{ll}b f & \text { base fluid } \\ n f & \text { nanofluid } \\ p & \text { particle } \\ c h & \text { channel } \\ m & \text { mixture }\end{array}$

